\title{
Accurate SIMS Doping Profiling of Aluminum-Doped Solid-Phase Epitaxy Silicon Islands
}

\author{
Yann Civale, ${ }^{\mathrm{a}, \mathrm{z}}$ Lis K. Nanver, ${ }^{\mathrm{a}}$ Stefano G. Alberici, ${ }^{\mathrm{b}}$ Andrew Gammon, ${ }^{\mathrm{b}}$ and \\ Ian Kelly ${ }^{\mathbf{b}}$
}

${ }^{a}$ Laboratory of Electronic Components, Technology, and Materials, Delft Institute of Microsystems and Nanoelectronics-DIMES, Delft University of Technology, 2628 CT Delft, The Netherlands

${ }^{b}$ Evans Analytical Group, Brunel University, Uxbridge UB8 3PH, United Kingdom

\begin{abstract}
A procedure has been implemented for a quantitative aluminum-doping profiling of $\mu \mathrm{m}$-scale aluminum-induced solid-phaseepitaxy (SPE) Si islands formed at $400^{\circ} \mathrm{C}$. The aluminum concentration was measured to be $1-2 \times 10^{19} \mathrm{~cm}^{-3}$, which is about 10 times higher than previously reported electrical activation levels. The elemental concentration was measured by secondary-ionmass-spectroscopy (SIMS) on arrays of SPE Si islands grown by a recently developed process that allows control of the island geometry.

(C) 2008 The Electrochemical Society. [DOI: 10.1149/1.2836739] All rights reserved.
\end{abstract}

Manuscript submitted November 8, 2007; revised manuscript received December 26, 2007.

Available electronically January 28, 2008.

Low-temperature $\mathrm{Si}$ crystallization techniques ${ }^{1,2}$ are attracting wide attention due to their many potential applications, such as semiconducting nanowires, ${ }^{3-5}$ thin-film transistors, ${ }^{6}$ interconnects, ${ }^{7}$ and shallow-junction formation. ${ }^{8}$ One method that has proven itself in actual device fabrication is the use of metals like nickel and aluminum to mediate the transport of $\mathrm{Si}$ and thus lower the crystallization temperature of $\mathrm{Si}^{9}{ }^{9}$ The doping of the resulting monocrystalline $\mathrm{Si}(\mathrm{c}-\mathrm{Si})$ by the metal is an important factor for understanding and predicting the device performance, but up until now little quantitative information has been available on this subject. In the case of $\mathrm{Al}$, substitutionally incorporated dopants will act as acceptors. This means that the Al-mediated Si crystallization also offers a lowtemperature means of creating p-doped regions. In the literature, the incorporated Al-concentration is often assumed to be above the equilibrium $\mathrm{Al}$ solid solubility in $\mathrm{Si}$ that is extremely low at temperatures below $500^{\circ} \mathrm{C}$, slightly above $10^{18} \mathrm{~cm}^{-3} \cdot{ }^{10}$ In principle, the concentration of $\mathrm{Al}$ in $\mathrm{Si}$ can be profiled by secondary-ion-massspectroscopy (SIMS) analysis. However, in the Al-mediated c-Si material the size of the crystals is typically smaller than the SIMS analysis area and the dimensional control is poor. ${ }^{11,12}$ Moreover, in systems where large c-Si areas are grown, the surface is usually not uniform enough to allow an accurate SIMS analysis.

In this article, the Al-doping concentration in a recently developed sub-500 ${ }^{\circ} \mathrm{C}$ aluminum-/amorphous-Si $(\alpha-\mathrm{Si})$ solid-phase epitaxy (SPE) process is extracted. This SPE process has been demonstrated to provide high-quality, ultra-abrupt, Al-doped $\mathrm{p}^{+}$-n elevated junctions down to nanoscale dimensions. ${ }^{13}$ Moreover, both the height and lateral dimensions of the crystallized regions can be well controlled by adjusting the layer-stack geometry and the thermal processing parameters. Information on the Al-doping level was acquired in our past work through the fabrication and electrical characterization of simple SPE-Si-based devices such as $\mathrm{p}^{+}$contacts, $\mathrm{p}^{+}-\mathrm{n}$ diodes, or $\mathrm{p}-\mathrm{n}-\mathrm{p}$ bipolar junction transistors. From these studies, the electrically active part of the $\mathrm{Al}$ doping in the bulk-Si of the islands was found to be about $2 \times 10^{18} \mathrm{~cm}^{-3}$. In the present work, the high degree of controllability of the growth mechanism has been used to create areas of SPE-Si islands that are suitable for a quantitatively correct SIMS profiling of the elemental $\mathrm{Al}$ concentration in the islands. A detailed description of the fabrication of the SPE-Si islands and the SIMS measurement procedure is given. The results show that the elemental concentration of Al in SPE-Si grown at $400^{\circ} \mathrm{C}$ is about $1-2 \times 10^{19} \mathrm{~cm}^{-3}$, which suggests that not all the incorporated $\mathrm{Al}$ dopants are electrically active.

${ }^{\text {z } E-m a i l: ~ y . c i v a l e @ d i m e s . t u d e l f t . n l ~}$

\section{Experimental}

Fabrication of SIMS analysis area.- The process flow used for fabricating an SPE Si-island array with a total area of about 60 $\times 60 \mu^{2}$ and containing 90 similar islands, each approximately $1.4 \times 1.4 \mu^{2}$ in size, is presented in Fig. 1. First, $1.4 \mu \mathrm{m}$ wide contact windows were opened by conventional lithography through a $30 \mathrm{~nm}$ thick thermal silicon dioxide $\left(\mathrm{SiO}_{2}\right)$ to the $\langle 100\rangle \mathrm{Si}$ substrate by using buffered hydrofluoric acid (HF) 1:7. Then, the native $\mathrm{SiO}_{2}$ was removed from the $\mathrm{Si}$ surface by dip-etching in HF $0.55 \%$ immediately followed by the physical vapor deposition (PVD) of first $200 \mathrm{~nm} \mathrm{Al}$ (containing 1\% Si) and then $20 \mathrm{~nm} \alpha$-Si. Both layers were deposited by using an argon flow of $100 \mathrm{sccm}$ at room temperature and without vacuum break in order to prevent the formation of an aluminum oxide $\left(\mathrm{Al}_{2} \mathrm{O}_{3}\right)$ interface. The $\mathrm{Al} / \alpha$-Si layer stack was then patterned using reactive-ion etching to form $5 \times 5 \mu \mathrm{m}^{2}$ large islands around the contact windows, in order to provide the optimal supply of Si for exactly filling the whole contact window with SPE-Si. In this manner, a practically ideal SPE-Si growth selectivity can be achieved with respect to the competing process of $\mathrm{Si}$ nucleation on the $\mathrm{SiO}_{2}$ in which the windows are etched. ${ }^{14}$ The epitaxy itself is induced by a thermal anneal at $400^{\circ} \mathrm{C}$ for $40 \mathrm{~min}$ in a $\mathrm{N}_{2} / \mathrm{H}_{2}$ (10:1) mixture at atmospheric pressure. After the growth, the aluminum transport layer was removed in a solution of diluted

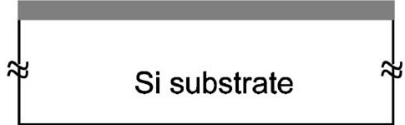

(a)

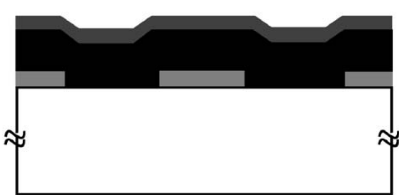

(c)

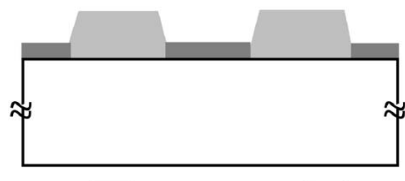

(e)

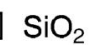

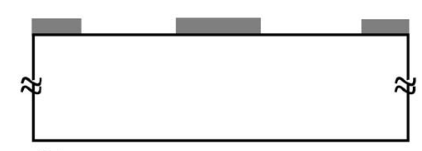

(b)

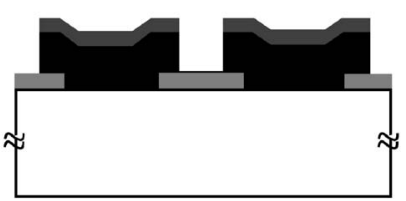

(d)

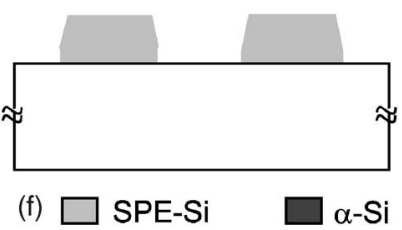

Figure 1. SPE process flow: (a) thermal oxidation, (b) contact window definition, (c) Al/ $\alpha-\mathrm{Si}$ PVD deposition, (d) Al/ $\alpha-\mathrm{Si}$ layer-stack patterning, (e) SPE-Si island growth and transport layer removal, and (f) oxide removal. 


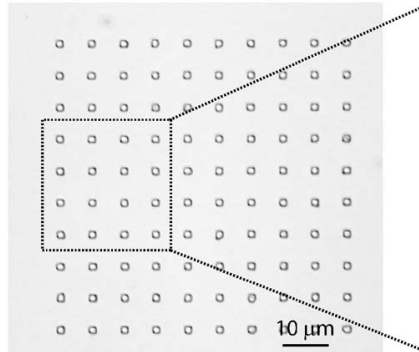

(a)

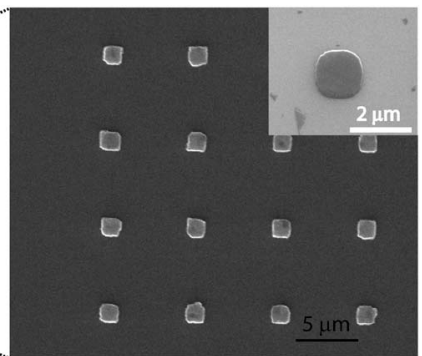

(b)
Figure 2. SEM micrograph of SIMS analysis area: (a) the whole 60 $\times 60 \mu^{2} \mathrm{Si}$ area including $100 \mathrm{SPE}-\mathrm{Si}$ islands grown at $400^{\circ} \mathrm{C}$ and (b) a close-up of 16 islands. The processing parameters have been chosen in such a manner that location control and selectivity of the SPE-Si growth is excellent and no Si nucleation is observed on the silicon oxide. The inset shows the SEM micrograph of a single SPE-Si island.

$\mathrm{HF} 0.55 \%$. Moreover, the remaining $\mathrm{SiO}_{2}$ was also removed (by soft HF 1:7) in order to avoid any possible SIMS artifact connected to charging effects during the SIMS sputtering: considering that the total SIMS acquisition area $\left(60 \times 60 \mu \mathrm{m}^{2}\right)$ is much larger than the total area of the SPE-Si islands $(\sim 4.5 \%$ of the total analysis area), the risk associated with charging could not be ignored. The SPE-Si island height, determined by the thickness of the $\mathrm{Al}$ transport layer, ${ }^{9}$ was about $200 \mathrm{~nm}$. An SEM micrograph of the as-obtained Si surface for SIMS analysis is shown in Fig. 2. It confirms that with this process it is possible to choose the growth parameters (time, temperature, and $\mathrm{Al} / \alpha-\mathrm{Si}$ layer-stack patterning) in such a way that a highly selective growth in the windows is reliably achieved. Moreover, the flat surface of the islands is also clearly shown. The fact that the Si deposited by PVD is entirely consumed by the epitaxial growth in the contact windows, and no Al-rich polycrystalline $\mathrm{Si}$ islands are randomly deposited on the surrounding dielectric, makes it possible to give an SPE-island-related analysis of the SIMS data. A study on the island size distribution indicated an average width of $1.4 \mu \mathrm{m} \pm 0.056(\sigma)$, demonstrating the high homogeneity of the SPE-Si properties.

A dynamic-SIMS (D-SIMS) analysis was performed using an $\mathrm{O}_{2}^{+}$ beam, a primary ion beam of $5 \mathrm{keV}$, and an angle of incidence of $\sim 45^{\circ}$. The Al-concentration detection limit was $4 \times 10^{13} \mathrm{~cm}^{-3}$. A calibration has been performed by measuring ion-implant standards to obtain the relative sensitivity factors, which convert the impurity secondary ion intensity into atom density. ${ }^{15}$ With this calibration technique, commonly used in the case of impurity concentration lower than the dilute limit ( $1 \%$ atomic density), there is practically no influence on the $\mathrm{Al}$ to Si ratio used for the SIMS quantification, as the pure Si signal in the end does not change when scaling down the D-SIMS raster area. During the D-SIMS measurement, material is sputtered from both the SPE islands and the Si of the surrounding substrate. To make sure that the quality of the $30 \mathrm{~nm}$ thick thermal $\mathrm{SiO}_{2}$ was good enough to prevent Al-dopant diffusion to the $\mathrm{Si}$ substrate during the epitaxy process, an area of a few hundreds of $\mu \mathrm{m}^{2}$ large Si region without any contact windows was also prepared for SIMS analysis.

\section{Results and Discussion}

The results of the SIMS Al-profiling analysis are presented in Fig. 3. The measurement of the nonpatterned sample given in Fig. 3a shows that the background Al-concentration doping is no more than $10^{13} \mathrm{~cm}^{-3}$, i.e., there is no $\mathrm{Al}$ diffusion through the $30 \mathrm{~nm} \mathrm{SiO}$ surface isolation layer into the bulk $\mathrm{Si}$. A narrow Al-contamination spike is, however, visible within the top $20 \mathrm{~nm}$ of the surface, presumably related to Al-surface contamination prior to SIMS, for example from the layer-stack removal steps. In any case, this contamination peak does not have an impact on the analysis of the Al-profile measured on the sample patterned with SPE islands: as seen in Fig.
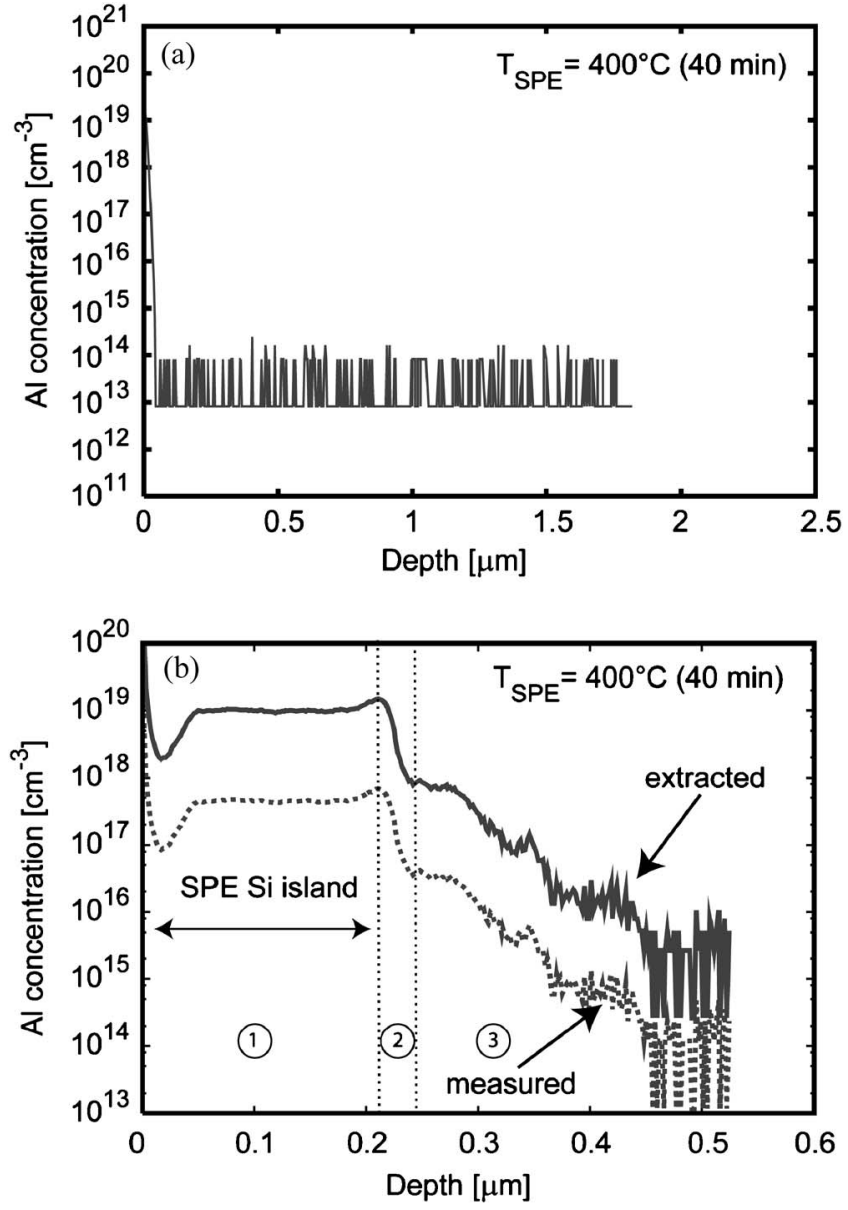

Figure 3. (a) Measured background Al-doping profile determined by SIMS on a nonpatterned $\mathrm{Si}$ region covered with $30 \mathrm{~nm}$ thick $\mathrm{SiO}_{2}$ during SPE Si growth process. (b) Measured and extrapolated Al-doping profile determined by SIMS of a Si region containing an array of $90 \mathrm{SPE}-\mathrm{Si}$ islands. A uniform Al doping in the SPE-Si islands (region 1) is in the range of $10^{19} \mathrm{~cm}^{-3}$. An abrupt decrease of the $\mathrm{Al}$ concentration is observed at the interface with the Si substrate (region 2). A gradual doping transition is observed, presumably due to sputtering-induced Al-injection into the underlying Si (region 3).

$3 \mathrm{~b}$, the top $20 \mathrm{~nm}$ of this profile can be disregarded while a uniform Al-concentration of about $4.5 \times 10^{17} \mathrm{~cm}^{-3}$ is measured up to a depth of about $200 \mathrm{~nm}$ in region (1), which corresponds to the height of the SPE islands. As stated in the previous section, a SIMS calibration technique was chosen particularly for the measurement of low concentration levels. Thus, the quantification signal scales in proportion with the relative area of the $\mathrm{Si}$ islands. Consequently, as the SPE-Si islands cover only $4.5 \%$ of the total analysis area, the Al concentration in the Si formed by SPE can be estimated as 1-2 $\times 10^{19} \mathrm{~cm}^{-3}$. In the following region (2), the SIMS profile displays a sudden drop in $\mathrm{Al}$ concentration, by more than one order of magnitude over a depth of $\sim 30 \mathrm{~nm}$. A more gradual decrease of doping is then observed in region (3). It is highly likely that the doping tail in regions (2) and (3) is the result of knock-on and/or differential sputtering effects. This is supported by the fact that previously reported electrical doping profiling by capacitance-voltage measurement techniques have indicated that the SPE island to Si substrate forms an ultra-abrupt Al-doped junction at $400^{\circ} \mathrm{C}^{16}$

The value of the SPE-island $\mathrm{Al}$ doping determined here is well above the equilibrium solid-solubility limit, $3 \times 10^{18} \mathrm{~cm}^{-3}$ at $400^{\circ} \mathrm{C}^{17}$ which is understandable in view of the fact that SPE is a nonequilibrium process. In the past we have reported on the electrical measurements of the resistivity of the SPE material: a sheet resistance of $R_{\mathrm{sq}} \approx 4 \mathrm{k} \Omega$ was found in an SPE layer $150 \mathrm{~nm}$ in 
height. Assuming mobility values similar to that of Al-implanted $\mathrm{Si}$, an active $\mathrm{Al}$ doping of $2 \times 10^{18} \mathrm{~cm}^{-3}$ was extracted. ${ }^{13}$ This indicates that the electrical activation level is less than $20 \%$ of the incorporation level. Moreover, the contact resistance of the Al metallization to the SPE-islands was measured using specially processed Kelvin structures where the SPE-Si surface was not oxidized before the deposition of the test structure Al-interconnect layer. ${ }^{16,18}$ The measured contact resistance, of about $10^{-7} \Omega \mathrm{cm}^{2}$, was much lower than what would be expected for an active doping around $10^{18} \mathrm{~cm}^{-3}$ or even $10^{19} \mathrm{~cm}^{-3}$. This suggests that there may be a segregation of $\mathrm{Al}$ at the surface of the SPE-Si islands that gives a higher electrical activity near the contact interface. It has not been possible to include the detection of this layer in a SIMS analysis due to the necessary cleaning of the samples before SIMS, performed in a nitric acid $\left(\mathrm{HNO}_{3}\right)$-based cleaning procedure that leads to oxidation of the SPE-Si islands.

\section{Conclusion}

Due to the high controllability of the developed SPE process, it has been possible to extract a reliable value of 1-2 $\times 10^{19} \mathrm{Al} \mathrm{at} / \mathrm{cm}^{3}$ for the $\mathrm{Al}$ concentration incorporated during the Al-mediated $\mathrm{Si}$ crystallization process at $400^{\circ} \mathrm{C}$. This type of approach offers a method for characterizing the concentration of metal incorporation in low-temperature metal-mediated Si crystallization regions.

\section{Acknowledgments}

The authors would like to thank Wim van der Vlist and Ruud Klerks for assistance in sample postprocessing. This research is supported by the Dutch Foundation for Fundamental Research on Matter (Stichting FOM).
The Delft University of Technology assisted in meeting the publication costs of this article.

\section{References}

1. D. He, J. Y. Wang, and E. J. Mittemeijer, J. Appl. Phys., 97, 1 (2005),

2. J. Y. Wang, D. He, Y. H. Zhao, and E. J. Mittemeijer, Appl. Phys. Lett., 88, 061910 (2006).

3. Y. Wang, V. Schmidt, S. Senz, and U. Gösele, Nat. Nanotechnol., 1, 186 (2006).

4. N.-K. Song, M.-S. Kim, Y.-J. Pyo, and S.-K. Joo, IEEE Electron Device Lett., 27, 899 (2006).

5. M. Zou, L. Cai, H. Wang, and J. Xu, Electrochem. Solid-State Lett., 9, G31 (2006)

6. C.-J. Su, H.-C. Lin, and T.-Y. Huang, IEEE Electron Device Lett., 27, 582 (2006).

7. V. Varadarajan, Y. Yasuda, S. Balasubramanian, and T.-J. King Liu, in IEDM Technical Digest, p. 149 (2006).

8. Y. Civale, L. K. Nanver, P. Hadley, E. J. G. Goudena, and H. Schellevis, IEEE Electron Device Lett., 27, 341 (2006)

9. O. Nast and S. R. Wenham, J. Appl. Phys., 88, 124 (2000).

10. V. Varadarajan, Ph.D. Thesis, University of California Berkeley, CA (2007).

11. T. Izumida, K. Okano, T. Kanemura, M. Kondo, S. Itoh, N. Aoki, H. Kawasaki, A. Kaneko, A. Yagishita, S. Inaba, K. Ishimaru, M. Nakamura, K. Eguchi, K. Suguro, and H. Ishiuchi, in IEEE 2006 Silicon Nanoelectronics Workshop Proceedings, Honolulu, HI, p. 127 (2006).

12. S. M. Hogg, P. Kluth, St. Lenk, M. Zhang, St. Trellenkamp, J. Moers, and S. Mantl, in Proceedings of the 14th International Conference on Ion Implantation Technology, p. 682 (2002).

13. Y. Civale, L. K. Nanver, and H. Schellevis, IEEE Trans. Nanotechnol., 6, 196 (2007).

14. Y. Civale, L. K. Nanver, P. Hadley, H. W. van Zeijl, E. J. G. Goudena, and H. Schellevis, Paper 0940-P05-04 presented at The Material Research Society Spring Meeting, San Francisco, CA (2006).

15. R. G. Wilson, F. A. Stevie, and C. W. Magee, Secondary Ion Mass Spectrometry, A Practical Handbook for Depth Profiling and Bulk Impurity Analysis, p. 3.1-1, John Wiley \& Sons, New York (1989).

16. Y. Civale, L. K. Nanver, and H. Schellevis, in Advanced Gate Stack, Source/Drain and Channel Engineering for Si-Based CMOS 2: New Materials, Processes, and Equipment, F. Roozeboom, E. Gusev, H. Iwai, D. Kwong, M. Özturk, and P. Timans, Editors, p. 97, The Electrochemical Society Proceedings Series, Pennington, NJ (2006).

17. F. A. Trumbore, Bell Syst. Tech. J, 39, 205 (1960).

18. L. K. Nanver, E. J. G. Goudena, and J. Slabbekoorn, in Proceedings of the International Conference on Microelectronic Test Structures, p. 241 (1996). 